\title{
Medical Imaging in Canada
}

- In 2009-2010, 1.4 million magnetic resonance imaging (MRI) exams and 4.2 million computed tomography (CT) exams were performed on Canadian patients.

- In 2009-2010, the numbers of MRI and CT exams increased by $6.9 \%$ and $6.2 \%$ respectively over the previous year.

- The number of medical imaging exams performed in Canada nearly doubled over the past six years.

- In 2009-2010, rates of MRI exams were twice as high in Alberta and Ontario (at 51 and 50 per 1,000 people, respectively) than they were in Prince Edward Island and Newfoundland and Labrador (26 and 25 per 1,000, respectively).

- Rates of CT exams also varied significantly between provinces, with highs of 197 per 1,000 people in New Brunswick, and 168 per 1,000 in Nova Scotia, compared with lows of 110 per 1,000 in British Columbia and 113 per 1,000 in Ontario.

- As of January 1, 2010, there were 281 MRI scanners and 484 CT scanners operational in Canada; an increase of $15 \mathrm{MRI}$ and $20 \mathrm{CT}$ scanners over the previous year and an increase of $124 \mathrm{MRI}$ and 143 CT scanners since 2004.

- Despite continued growth in the number of exams and machines, Canada performs fewer diagnostic imaging exams relative to population size than the average among countries in the OECD.
- Internationally, rates of MRI exams varied from a low of 13 per 1,000 in Korea to a high of 98 per 1,000 in Greece, while CT rates ranged from 60 per 1,000 in the Netherlands to 321 per 1,000 in Greece.

- Canada's rates of CT and MRI exams were higher than those in Denmark and Australia but lower than those in the United States and France. HQ 


\section{Vernacare.}

\section{Partner with a World Leader in Quality}

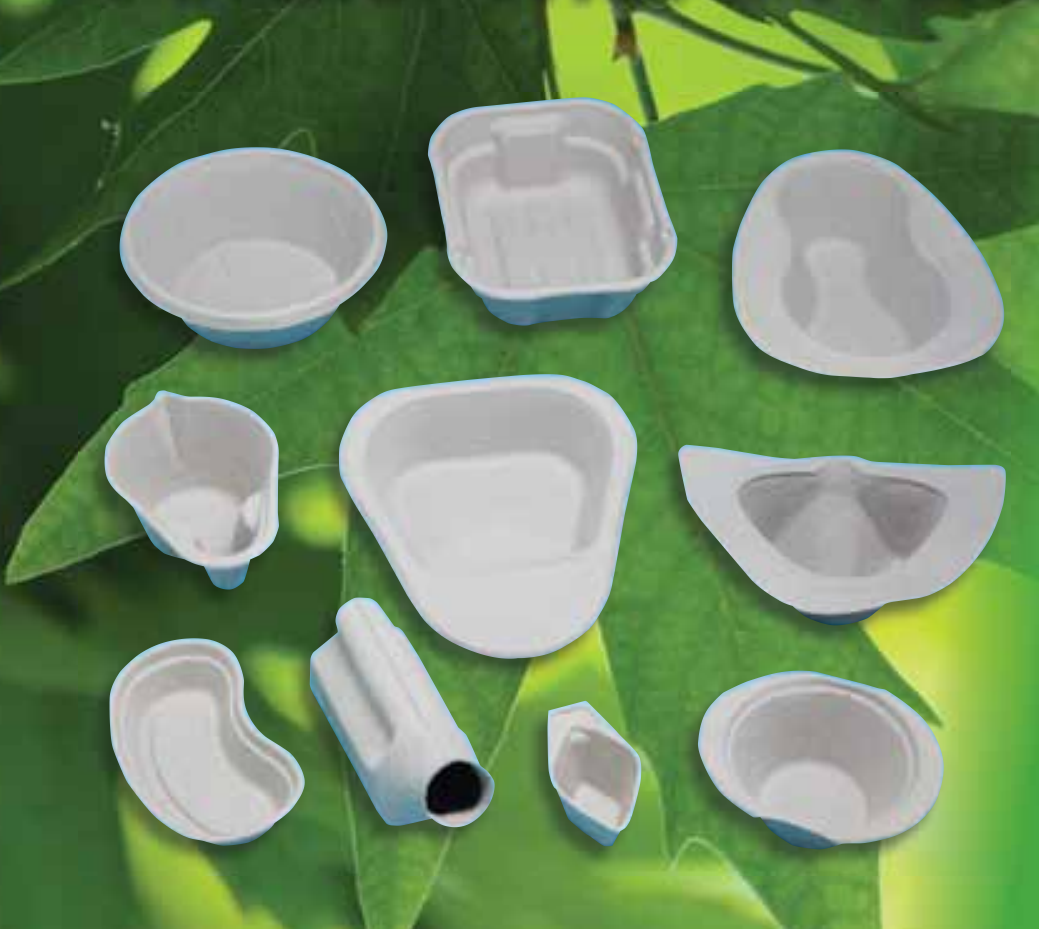

\section{Made from $100 \%$ recycled biodegradable}

post-consumer newsprint.

Vernacare's state-of-the-art Macerators are an ideal solution for safe, discreet and environmentally responsible elimination of human waste.

Setting the standard for excellence in Hospital Human Waste Management

Vernacare has been partnering with healthcare providers to deliver superior human waste management solutions for over 50 years.

\section{Discover the unique advantages:}

- Cost effective total human waste solutions

- Seamless distribution and service networks

- Elimination of utensil cleaning and disinfecting

- Reduction of the risk for cross-contamination

- Enhancing the quality of nursing

- Reducing the healthcare carbon footprint

Vernacare - Your Partner in Infection Control
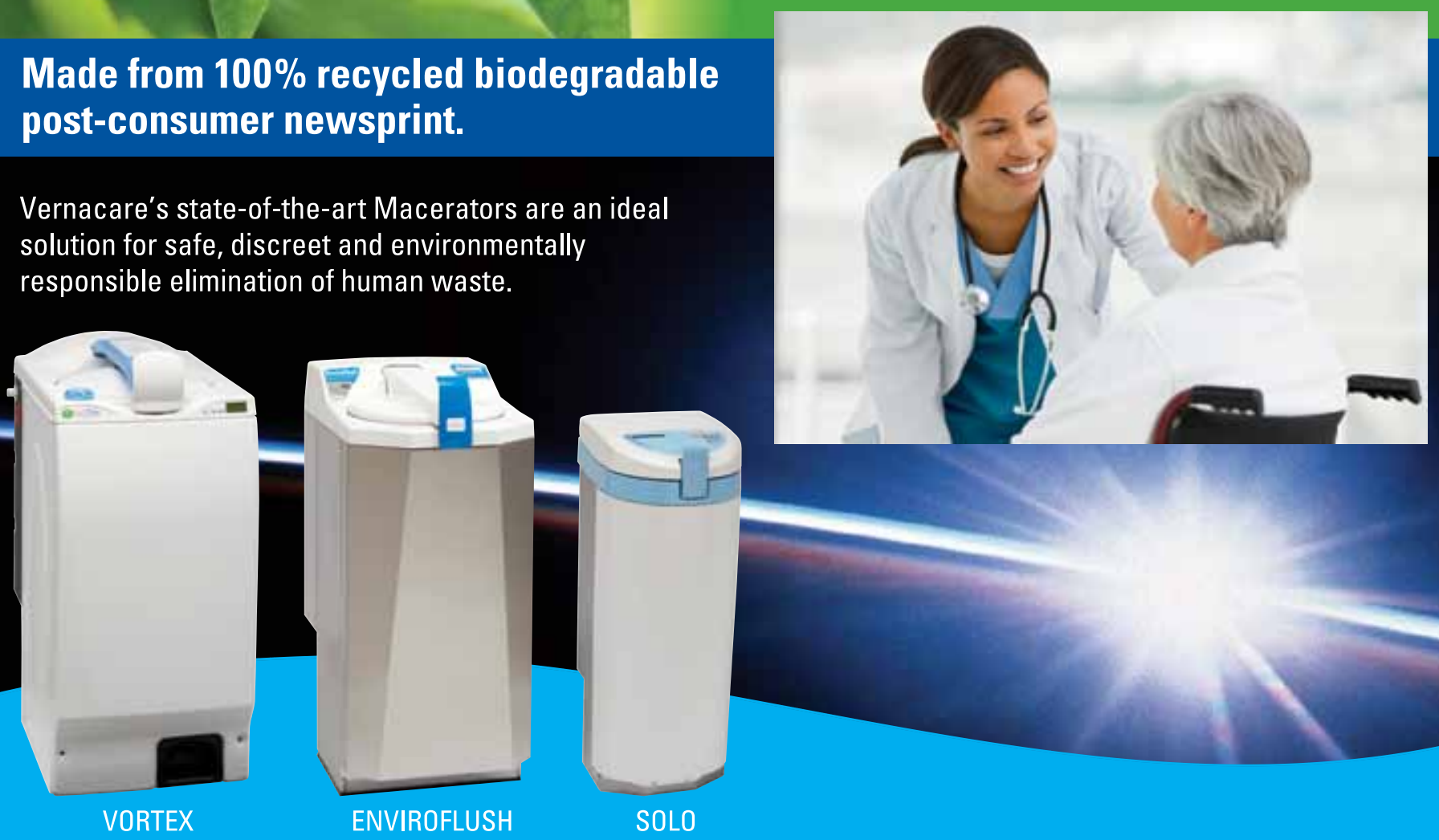

A WORLD LEADER IN HOSPITAL HUMAN WASTE MANAGEMEN

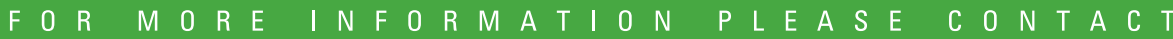




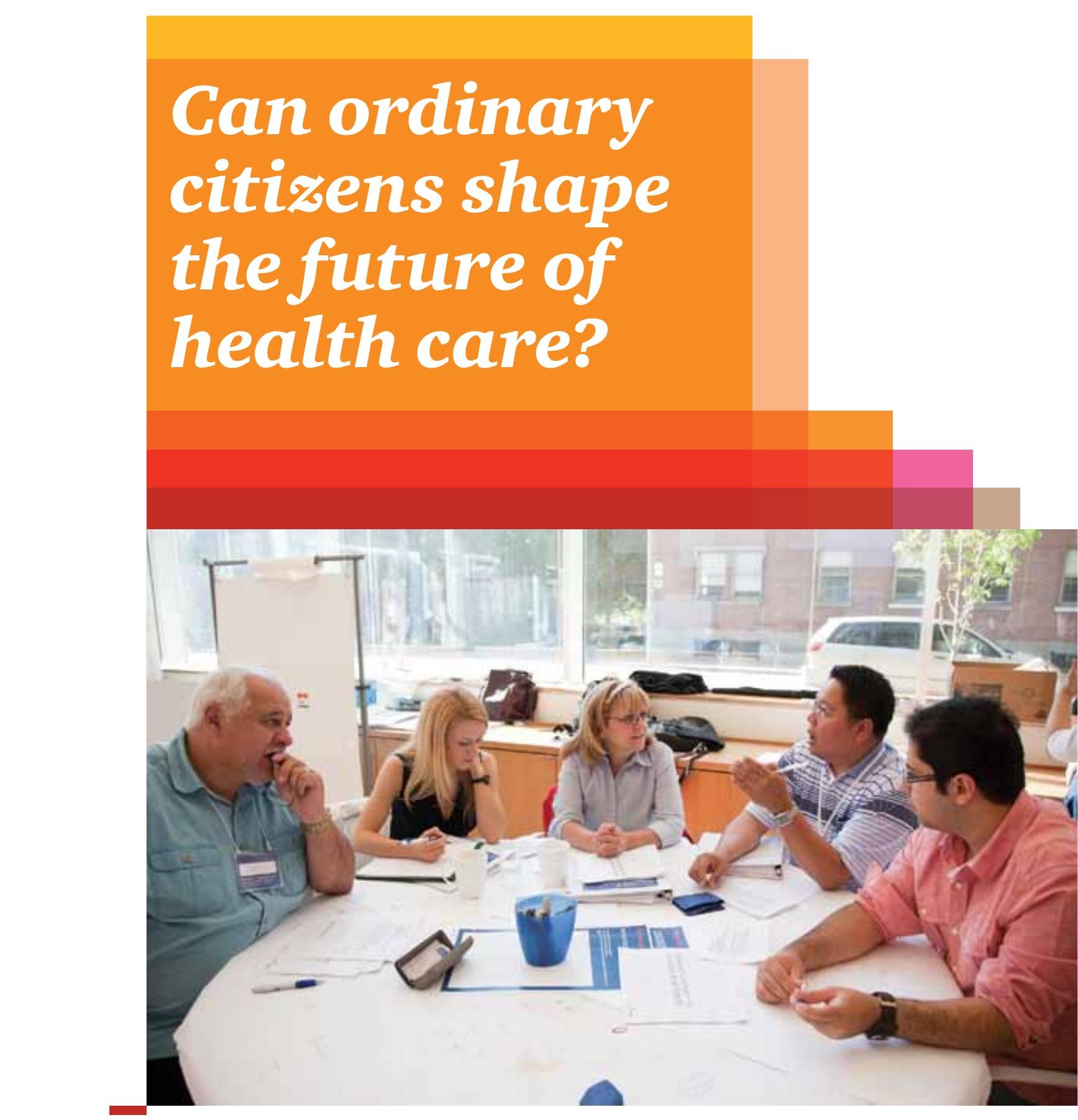

\section{pwc}

In response to the growing calls for major health care reform, $\mathrm{PwC}$ gathered 28 randomly selected citizens from across Ontario to learn about the health system and understand the challenges.

What did they recommend to ensure the sustainability of high-quality, accessible and publicly-funded health care? Read the report to find out: www.pwc.com/ca/shapethefuture

Follow the journey. Join the dialogue. Shape the future. 